\title{
"A Study To Evaluate The Effectiveness of Self Instructional Module on Knowledge And Practice Regarding Integrated Management of Neonatal And Childhood Illnesses Among Staff Nurses Working In Paediatric Wards of Selected Hospitals in Patna, Bihar"
}

\author{
Rohit Tongariya \\ Principal, Govt. ANMTC, Katihar (Bihar) \\ (Nursing Officer, Patna Medical College \& Hospital)-2015-2018 \\ Corresponding Email: rohit.tongariya1986@gmail.com
}

\begin{abstract}
:
Introduction: Children are our future and our most precious resources. Today's children are the citizens of tomorrow's world. The IMNCI case management component is mainly focused on the classification of the five most common causes of infant mortality (diarrhoea, pneumonia, malaria, measles and malnutrition), identification of treatment, accurate treatment or timely referral, counselling of the mother and giving follow-up care.

Method \& Material: An evaluative research approach and quasi-experimental research design was adopted. 150 nurses working in pediatric wards of selected hospitals at Patna were selected for the study by using purposive sampling technique. By using knowledge questionnaires, and competency checklists questionnaires.

Results: The study reveals that out of $100 \%$ of nurses $3.3 \%$ of the nurses had good knowledge before Selfinstructional module; majority of the nurses $60 \%$ had average knowledge; $36.6 \%$ of the nurses had poor knowledge. Whereas majority of the subjects $76.7 \%$ had good knowledge, $23.3 \%$ nurses had average knowledge after a Self-instructional module in IMNCI. In competency $51.7 \%$ had moderate on practice, $38.3 \%$ had adequate knowledge on practice, and $10 \%$ of the nurses had inadequate knowledge on practice before the Selfinstructional module. Whereas majority of the nurses $83.3 \%$ had adequate knowledge on practice, $16.7 \%$ nurses had moderate knowledge on practice after the Self-instructional module on IMNCI.

Conclusion: There is a positive co-relation observed between the level of knowledge and practice regarding Integrated Management of Neonatal and Childhood Illnesses among staff nurses. The study revealed that Selfinstructional module improved the knowledge and practice regarding Integrated Management of Neonatal and Childhood Illness among Staff nurses.
\end{abstract}

Keywords:Knowledge, Practice IMNCI

\section{INTRODUCTION}

Children are our future and our most precious resources. Today's children are the citizen's of tomorrow's world. In other words, the children are the budding human resources and the future citizens of the nation. Healthy children are not only assets but also the stepping stone to build a strong and prosperous nation. Their survival and protection is prerequisite for the future development of humanity. Every child represents the unit of human capital. He/she has the potential to grow into a productive adult and contribute to the economic and social development of the country. The Integrated management of neonatal and childhood illness strategy is a broad strategy developed by WHO in collaboration with UNICEF, and it aims at reducing childhood deaths, illness, and disability, and improving growth and development. It combines improved management of childhood illness 
with aspects of nutrition and immunization in children below the age of five years.

\section{STATEMENT OF THE PROBLEM}

"A study to evaluate the effectiveness of Self Instructional Module on knowledge and practice regarding Integrated Management of Neonatal and Childhood Illnesses among staff nurses working in Paediatric wards of selected Hospitals in Patna, Bihar"

\section{OBJECTIVES}

1) To assess the knowledge regarding Integrated Management of Neonatal and Childhood Illnesses among staff nurses before and after a Self instructional module.

2) To assess the practice regarding Integrated Management of Neonatal and Childhood Illnesses among staff nurses before and after a Self instructional module.

3) To evaluate the effectiveness of a Self Instructional Module based on Integrated Management of Neonatal and Childhood Illnesses among staff nurses.

4) To correlate the post test knowledge score with the practice score regarding Integrated Management of Neonatal and Childhood Illnesses among staff nurses.

5) To associate the post test knowledge score regarding Integrated Management of Neonatal and Childhood Illnesses among staff nurses with selected demographic variables.

6) To associate the post test practice score regarding Integrated Management of Neonatal and Childhood Illnesses among staff nurses with selected demographic variables.

\section{MATERIALS AND METHODS}

The present study evaluates the effectiveness of Self Instructional Module on knowledge and practice regarding Integrated Management of Neonatal and Childhood Illnesses among staff nurses. An evaluative research approach, quasi-experimental research design was adopted. 150 nurses working in pediatric wards of selected hospitals at Patna were selected for the study. Purposive sampling technique is used. The data is collected by structured interview questionnaire and an observational checklist. This structured interview questionnaire contains 40 questions and an observational checklist consists of 20 questions.

\section{Description of data collection instruments}

Section-I Baseline data

Section-II Knowledge questionnaire regarding integrated management of neonatal and child hood illnesses.

Section- III Structured Observational checklist on integrated management of neonatal and child hood illnesses.

Section- IV Self Instructional Module on integrated management of neonatal and child hood illnesses.

\section{RESULTS}

The study reveals that out of $100 \%$ of nurses $3.3 \%$ of the nurses had good knowledge before Selfinstructional module; majority of the nurses $60 \%$ had average knowledge; $36.6 \%$ of the nurses had poor knowledge. Whereas majority of the subjects $76.7 \%$ had good knowledge, 23.3\% nurses had average knowledge after a Self-instructional module in IMNCI. In competency $51.7 \%$ had moderate on practice, $38.3 \%$ had adequate knowledge on practice, and $10 \%$ of the nurses had inadequate knowledge on practice before the Self-instructional module. Whereas majority of the nurses $83.3 \%$ had adequate knowledge on practice, $16.7 \%$ nurses had moderate knowledge on practice after the Self-instructional module on IMNCI. There was a significant difference found $(\mathrm{P}<0.05)$ between the pretest mean score 11.8 $( \pm 3.6)$ and posttest mean score of knowledge 24.5 $( \pm 3.16)$ and mean score pretest knowledge on practice $4.3( \pm 1.69)$ and posttest mean score $8.81(+1.56)$. The $t$ value for knowledge were 32.42 and 23.96 for practice which is greater than table value $(1.655)$ at $\mathrm{p}<0.05$. It shows that the self instructional module was effective in improving the knowledge and practice regarding Integrated Management of Neonatal and Childhood 
Illnesses among staff nurses. There is a positive corelation observed between the level of knowledge and practice regarding Integrated Management of Neonatal and Childhood Illnesses among staff nurses. there is no association between age, gender, religion, professional education, years of experience and source of information regarding Integrated Management of Neonatal and Childhood Illnesses with the knowledge score of staff nurses. there is no association between age, gender, religion, professional education, years of experience and source of information regarding Integrated Management of Neonatal and Childhood Illnesses with the practice score of staff nurses.

\section{CONCLUSION}

From the findings of the present study, it is concluded that the level of knowledge and practice regarding Integrated Management of Neonatal and Childhood Illness among staff nurses was inadequate during the pre-test assessment. However, the findings in the post-test, knowledge and practice have improved and the scores indicated an adequate level of knowledge and practice among staff nurses. The improvement is due to the administration of the Self instructional module. Therefore the knowledge and practice of the staff nurses can be further improved by providing on-going teaching and health education programmes.

\section{LIMITATIONS OFTHE STUDY}

- There was no actual observation of the practical performance of the staff nurses but only their responses on practice.

- The duration after the study post test assessment was very small; so long term retention cannot be measured.

\section{RECOMMENDATIONS}

A similar study can be undertaken with larger samples to validate and generalize the findings of the study.

The present study can be replicated in similar and different settings.

A similar study can be conducted among school students and non-medical college students.

A study can be conducted to assess the knowledge and practice of mothers of under five children regarding Integrated Management of Neonatal and Childhood Illnesses in community.

A similar study can be undertaken by using different teaching methods.

A similar study can be conducted on various aspects of

IMNCI guideline

\section{REFERENCES}

1. K Park "Text Book of preventive and social medicine", $18^{\text {th }}$ edition, Banarsidas Dhanot publishes pg 235

2. "New Health policy and planning frame work part $1^{\text {st }}$ working version", pg 235 in Jan30 , 2005

3. Deshmukh (2008). Perception and health care seeking about Newborn Danger signs among mothers Indian Journal of pediatrics 75(1) 324 326.

4. National Research For Institute of child health and Development in Tokyo ", volume 48 [8] pg 404-409 2206 August 2005 "

5. WHO Department of child and Adolescent Health and Development [CAH], "Student handbook of IMNCI 2003"

6. Isabelle.de.Zoysa, Nita Bhandari, Naseema Akhtar Maharaj K Bhan; science direct; case seeking for illness in young infants in an urban slum in India, Volume 47, issue 12, pages 2101$2111,1998$.

7. Sinhababu A. Mukhopadhyay DK, Panja TK, Saren, Mandal NK, et.al., (2010) A study on infant and young feeding practices, Journal of Health Population and Nutrition. 28(6) 294-9

8. Thompson. M.E, and Harutyunyan, (2009). Impact of Community based IMCI. Health Policy Plan. 24(2).45-46

9. Athumanijuma, (2007). Knowledge, Attitude, practice of mothers on symptoms and signs of 
IMNCI strategy. official publication of medical student's Association 73(7).1-5.

10. Kelly JM, Rowe AK, Onikpo F,Lama M., Cokouits F,et.al (2007). Care takers' recall of Integrated Management of Childhood Illness counselling messages in Benin. Published online 2009 Oct 1. doi: [10.1186/1471-2431-9-62

11. Neerugupta, (2007). An Evaluation of diarrheal disease and Acute respiratory infection. Indian Journal of Pediatrics. 74 (5) 234-236

12. Santosh K, Bhargava.Center for Newborn care. Department of Pediatrics, SL Jain Hospital. The Challenge of Neonatal Mortality in India. Indian Pediatrics 2004; 41:657-662.

13. Srivastava NM, Awasthi S, Agarwal GG, Careseeking behavior and out-of-pocket expenditure for sick newborns among urban poor in Lucknow, northern India: a prospective follow-up study. Indian J Comm Med 2009: Apr 2; 61.

14. SY, Holloway KA, Ivanovska V, Muhe L, Lambrechts $T$. Does shortening the training on integrated management of childhood illness guidelines reduce its effectiveness? A systematic review. Health policy plan. 2011 Apr 23. Available from:http://www.ncbi. nlm.nih.gov/pubmed.

15. Lulseged $S$, Integrated management of childhood illness: a review of the Ethiopian experience and prospects for child health , Etiopian medical Journal , 2002 Apr;40(2):187-201

16. Christiane Horwood, Kerry Vermaak, Nigel Rollins, Lyn Haskins, Phumla Nkosi, and Shamim Qazi, An Evaluation of the Quality of IMCI Assessments among IMCI Trained Health Workers in South Africa, PLoS ONE. 2009; 4(6): e5937 